\title{
Analysis on the Beauty of Ancient Chinese Sculpture Arts
}

\author{
Lu Cheng ${ }^{1}$, Ge Cheng ${ }^{2}$ \\ ${ }^{1}$ ShangHai Publishing and Printing College, China \\ ${ }^{2}$ Shanghai Sibo vocational and Technical College, China
}

Keywords: Likeness, Decoration, Painting, Freehand, Line, Symbol, Gentle.

\begin{abstract}
China's history of 5,000 years has created a splendid art and culture. The unique stylistic language of Chinese sculpture is shining in the history of sculpture in the world. The beauty of ancient Chinese sculpture lies in the beauty of the expressiveness, the beauty of decoration, the beauty of painting, the beauty of lines, the beauty of lines, the beauty of gentleness. Ancient Chinese sculpture art has its unique oriental art style, emitting a brilliant light in the world art treasures.
\end{abstract}

\section{Foreword}

China's history of 5,000 years has created a brilliant art and culture. Ancient Chinese sculpture is rooted in the profound cultural soil of the Chinese. With the development of ethnic arts and culture for thousands of years, it has development and evolved. The entire Chinese nation's cultural accomplishment, aesthetic awareness, way of thinking, aesthetics and philosophy of the complete art system. The unique ancient Chinese sculpture art shine in the history of the world sculpture. Its unique oriental art style radiates a splendid light in the world art treasure.

\section{The Beauty of Ancient Chinese Sculpture Arts}

\subsection{Likeness.}

The artistic spirit of China has created oriental art language, and the traditional Chinese art pursues the beauty of likeness. chinese art focus on 'likeness' compare to "figure", spiritual resemblance is the core of Chinese art. The Chinese sculptural language perfer less is more,just like chinese traditionl painting, chinese sculpture emphasis is on both spirtual and formal ,and the pursuit of similar beauty. Chinese traditional philosophical thinking determines the artistic features of ancient Chinese sculpture. The Chinese traditional philosophical thinking mode seeks two unities changed intoas a unified whole, that is, the monistic theory of the universe. Western traditional thinking holds that the world is two-dimensional and analytic dualism. The difference of Chinese and Western modes of thinking has formed a scientific mode of thinking that western culture values logical reasoning, which lays an important foundation for the development of western sculpture. Western art emphasizes reproduction, imitation and realism, pursuing the unity of beauty and truth,, Western ancient sculpture emphasizes physical proportion, structure, demeanor, the true beauty of the pursuit of reproduction; Chinese culture emphasizes intuitive imagery thinking, through intuition, sentiment understanding of the universe. Eastern thinking beyond logic, rational thinking more emphasis on perception. Eastern perception of the formation and the Western culture which are different cultural characteristics, reflected in the arts, such as sculpture, painting is of course the formation of different artistic language traits. The Chinese sculpture language seeks the similar beauty, paying attention to expressing the spirit, the rhyme and the image. Throughout the ancient Chinese sculpture art, its figure is not precise and exactly like the shape, but the pursuit of the appearance of style and meaning. Take the stone sculptures of the Huo T'u-tomb in the Han Dynasty as an example. The appearance is rough and the language is practiced. There is no carving of western sculpture art, but its style is magnificent, vigorous, magnificent, and extremely dripping. Embodies the bold momentum, simple, eager life vitality. Chinese seek the artistic mode of thinking of "spirit" by "form", pursue the "vivid 
portrayal" and "shape the spirit". It is emphasized that the beauty of the sculpture spirit is the most prominent artistic feature of the ancient Chinese sculpture art.

\subsection{Decoration.}

Ancient Chinese sculpture with a strong decorative style. Ancient Chinese sculpture originated in the ancient arts and crafts, one of the characteristics of arts and crafts is decorative, ancient Chinese sculpture with natural decorative art style. Whether it is the bronze art of the Shang period, the religious sculptures of the Five Dynasties and the Ten Kingdoms, the porcelain of the Tang and Song dynasties, or the architectural decorations of ancient dynasties all exuded a rich decorative taste.The ancient Chinese buddha statue rich in decorative language and statues, which are different from the Western realistic sculptures. Stylized ornamental language aesthetics is presented in various stances and gestures such as standing, sitting, squatting and lying without emphasizing the realistic expression and planarization of the structure volume of the human body Modeling practices.Buddhist symmetrical seated, double-collar dangling salamander patterned clothes, so that it shows a strong decorative; Buddhist art from ancient India, China's Buddhist sculptures from ancient India Gandhara, Ma Buddhist and other regions and times .India and Southeast Asia Buddha shape with a strong decorative beauty, multi-arc, the feminine style of its decoration, was graceful posture. Chinese traditional Buddhist statues draw on the styling characteristics of Indian statues while combining with the local religious culture, without the graceful posture of the arc, decorative features is elegance anddedication. The use of color in traditional Chinese sculpture is strongly decorative, emphasizing the richness and beauty of color. Such as Dunhuang Grottoes color with color language, with red, vermilion, pink green, blue, etc., and then use black and silver black outline, colorful and strong, showing a rich decorative style. Tang Sancai pottery with beautiful yellow, brown, green three colors, the color was shades change, mutual infiltration, mottling dripping decorative effect;Folk painting emphasizes the beauty of color decoration. For example, the traditional clay sculpture-- clay dog that has been published so far has the characteristics of ancient, absurd, black with the colors of red, green, yellow and white. A strong contrast can make the overall feeling of harmony, with a strong decorative style.

\subsection{Painting.}

The beauty of Chinese ancient sculpture,which is an oriental unique aesthetic taste that accords with the Chinese ancient people's appreciation habit. They make sculpture art from the perspective of painting art. In ancient China, the stylized pattern of the sculpture is expressed in a decent manner by using lines and colors. Compared with the western realistic sculpture, the essence of the sculpture is a kind of painting expression.Instead of emphasizing volume, space and block surface, Chinese ancient sculptures pay attention to the rhythm contour lines and body lines, which is consistent with the traditional Chinese painting.These lines are the same as the painted lines, which are processed through the generalization and elaboration. This is totally different from the way that Western classical sculptures emphasize the expression of blockiness and sense of space. Western sculpture has a strong sense space, the ancient Chinese sculpture is characterized by smooth surface. Most of the ancient Chinese beasts sculptures are mostly shaped with a large outline. There is big difference betweenthe traditional western sculptures and ancient chinese sculptures. There is no turning point, depth and space for the realistic sculptures .This kind of painting-like sculpture language emphasizes more the sounds of the outside shape, which is consistent with the ancient Chinese painting spirit.In the meantime, the ancient Chinese sculpture is traditional painted sculpture. In the ancient sculptures, from the Terracotta Warriors of Qing Dynasty to the Wooden figurines of Han Dynasty, buddha statues of the Five Dynasties and Tang Dynasty to the woodcut sculptures of Ming and Qing Dynasties,which are all painted sculpture combinations,this kind of language,determines the ancient chinese sculpture and painting emphasize "spirit first",the chinese sculpture art present of the taste of painting.

\subsection{Freehand.}

"Freehand" is an artistic expression of traditional Chinese painting, an artistic view of Chinese 
traditional aesthetics, this aesthetic system that is totally different from western aesthetics. "Meaning" is the subjective emotion produced by people in understanding the objective things. "Freehand" refers to the subjective will, emotion into the creation, the emotion into the mind, not deliberately reproduce the objective appearance, the expression of artistic interest.Ancient Chinese sculpture and ancient paintings pursue the beauty of the verve.Such as the use of black and white colour, lines of chinese painting is famous for less is more, in the pursuit of the same interesting expression. Western sculpture in pursuit of the accuracy of the structure, in the repeated scrutiny of the proportion of the structure, the natural art of the moment lost the inspiration beauty of interest.Chinese traditional sculpture emphasizes vividness, does not emphasize the accuracy of the modeling structure, the pursuit of the expressiveness of modeling, emphasizes the charm of people and animals by exaggerating the deformation, and makes the imagery taste intriguing.As the ancient Chinese lions concise summary of the shape, refining, the lion is not the real world is even more momentum, mighty. There is Tang dynasty lion in Shanghai Museum, a head of the face of the lion, the wind was scattered mane, the face containing mighty but not exposed, the shape of the atmosphere is extremely vivid. With the same lions, the proportion of Western stone beast its structure can be described as exhaustive but the lack of the essence of the East lion, gas, God. Compared with western sculptures, the sculptures and figurines of the Han Dynasty can be described as "simple". The artistic expression of quick and easy is the language of the atmosphere. Habitat like listening to their voice.

\subsection{Lines.}

Oriental art is line-oriented art. In Chinese art, calligraphy, painting and sculpture all embody oriental charm with lines as beauty.Chinese ancient sculptures are made of lines and lines are very expressive styling ways. Compared with the Greek sculptures characterized by clumps, they are two different forms of artistic expression. The beauty of lines in Chinese sculpture does not rigidly adhere to the shape of the body, which is not same aesthetic sense as the Western mass sculpture, reflecting the aesthetic spirit of oriental art.Chinese ancient statues of sculpture is not volume modeling, is through the "Cao Yi water" lines reflect the human body structure.Such as Maijishan Buddha niche statues, the lines of the performance of superb realm, hard stone is carved into a light and soft fabric, like satin-like light, the stone has a silky luster, human body The movement is cleverly shown through the lines, and the beauty and vitality of the lines themselves are also fully revealed through the rhythm and rhythm of the lines.In the manifestation of the mighty and brave personality of the "generals", ancient Chinese craftsmen used lines which like steel to reflect their muscle structure. In shaping the "Guanyin" full of calm state of demeanor, the use of smooth and full line language sculpture.Different times line language is also different, mostly in the Han Dynasty sculpture lines rough and powerful,Such as Huo Qubing grave animal modeling language, Wei, Jin and Northern and Southern Dynasties sculptures show "skull " style, which was the social turmoil of the past long, the people's life is difficult, the sculptures were thin and lean style.This is exactly the opposite with the Tang Dynasty sculpture line, the Tang Dynasty sculpture such as Tang glory, full plump shape, the modeling lines are mostly full and elastic curve. Sturdy lines are hidden in fullness, magnificent, or apparently or subtly outward arcs. Several outwardly protruding arcs frame carved figures with a majestic, atmospheric tension.

\subsection{Symbol.}

Symbolism is an outstanding aesthetic feature in ancient Chinese sculpture. Ancient sculpture contains rich cultural connotation, lions, evil spirits, Tianlu, stone horse and so on have a certain level of emblem, a symbol of status, meaning auspicious spiritual connotation. The beast sculpture of ancient tomb mausoleums of the tombs of the beast its shape gives the authority power.As auspicious metaphor on horse stump sculpture portrait or animal style humorous and lovely. As a decorative architectural sculpture is to demonstrate its symbolic metaphor,The ancients pay attention to the shape must be intentional, intentional auspicious modeling principle, the Ming and Qing Dynasties building a lot of similar auspicious and metaphorical sculpture.Such as bees, plums, and many other animal sculptures that symbolize auspiciousness and longevity, such as turtles, cranes, dragons, elephants, lions, horses, etc., through specific sculptures Elements of longing for a better life,Pray for 
peace, bumper harvest, exorcism evil spirits. The Han Dynasty stone "horse riding chest slave," a symbolic approach to momentum defeat of the Huns. The whole sculpture style momentum powerful, rough rough pose is the perfect combination of artistic and symbolic model.

\subsection{Gentle.}

The ancient Chinese sculpture art gave birth to the Huaxia national civilization of thousand years and originated from the Chinese nation cultivated by civilization. Its warmth and national ethos is different from the bold and unrestrained western nomads, Reaction in the art and culture, the art style presents a gentle beauty, subtle beauty.From the history of the development of Chinese sculpture, we can see that the development of ancient Chinese sculpture art is also from the wild beauty to the gentle beauty.From the traditional themes of the lion sculpture can be seen: the Han Dynasty stone lions fierce and heavy, the lions of the Six Dynasties radiant, Tang Dynasty plump lions, the Song Dynasty mild and humble lions, the Ming and Qing dynasties Shishi is no prettier posture,tame gentle.Compared with Western ancient sculptures, the ancient Chinese sculptures are not as vivid as the Western classical sculptures. They are vivid but contain implicit meaning and contain endless meanings.Compared with Western ancient sculptures, the ancient Chinese sculptures are not as vivid as the Western classical sculptures. They are vivid but contain implicit meaning and contain endless meanings.No rattling, outward publicity of anger, but as the Chinese painting and calligraphy with the front of the pocket, leaving a long finish.Dunhuang Grottoes statues modeling, with smooth lines, giving gentle beauty, Shandong Qingzhou stone statue, introverted line modeling, "Xiu Gu Qingxiang" posture with literati thin and handsome, there are immortal refined elegance.The gentle and graceful beauty of ancient sculpture in our country reflects the multiple elements of Chinese national temperament, social and cultural tradition, geographical environment, philosophy and ethics.

\section{Summary}

Throughout the development of Chinese sculpture, in terms of its spirituality, it is mainly influenced by politics, religion and philosophy.For its modeling, it is mainly influenced by painting and shows its own way in images, abstraction, freehand brushwork and realism. Its wisdom and beauty have unique values that are different from the traditional Western systems. The sculpture of Qin and Han dynasties, elegant Wei and Jin Dynasties, the rich and charming of the Tang Dynasty and the grace of the Song Dynasty, the ancient Chinese sculpture of the beauty is oriental beauty, is the naturalization, which became into the chinese sculpture style.

\section{References}

[1] Tian Zibing. History of Chinese Arts and Crafts [M]. Shanghai: Oriental Publishing Center, 1999: 65, 97.

[2] Zong Baihua. Aesthetic Walking [M]. Shanghai: Shanghai People's Publishing House, 2005: 26, $56,78$.

[3] Yan Wenru. Chinese sculpture art just [M]. Guilin Guangxi Normal University Press, 2003: 37, 95, 113.

[4] Thin Song years. Chinese art history tutorial [M]. Xi'an Shaanxi People's Fine Arts Publishing House, 2000: 56, 57.

[5] lefthanzhong. Chinese folk art modeling [M]. Changsha: Hunan Fine Arts Publishing House 1992: 58, 91. 